\title{
ELLIPSIS AND INFORMATION STRUCTURE: EVIDENCE FROM ROMANIAN GAPPING
}

\author{
Gabriela Bîlbîie*
}

\begin{abstract}
The main goal of this paper is to investigate the information structure of gapping, a linguistic level which has been much less studied than syntax or semantics. Romanian is a good test case for such a study, since it displays a specific contrastive conjunction iar, which occurs frequently with gapping and which severely restricts the information structure ordering. We explain its high frequency with ellipsis by the fact that it shares several crucial constraints with gapping. Our data show that the contrastive pairs with iar do not have the same contribution: one pair contains contrastive topics, and the other foci. However, the order of the correlates in the source clause does not necessarily match the order of the remnants in the gapped clause. We use a QUD model, based on question-answer congruence, which is very useful for a careful investigation of the discourse and information structure of ellipsis.
\end{abstract}

Keywords: gapping, discourse, contrast, focus, contrastive topic

\section{Introduction}

While ellipsis has been a topic of interest for decades, the literature on ellipsis has mostly concentrated on the way the usual form/meaning mapping may be articulated with respect to ellipsis phenomena. Ellipsis seems to involve a form/meaning mismatch (significatio ex nihilo): on the one hand, part of the material necessary for the interpretation is missing in the syntactic structure ("incomplete" syntax), and on the other hand, the missing material is recovered from an antecedent in the context. Two main competing accounts have been proposed in the so-called syntax/semantics debate: on the one hand, structural approaches based on syntactic reconstruction, positing more abstract syntactic structures within theories of grammars that allow unpronounced phrases and heads (e.g. deletion accounts, cf. Ross 1967, Sag 1976, Hankamer 1971, Hartmann 2000, Merchant 2001, 2004, etc.); on the other hand, non-structural approaches based on semantic reconstruction, which supplement the theory of meanings, by creating or exploiting devices that can generate meanings in the absence of syntactic structure (Dalrymple et al. 1991, Ginzburg and Sag 2000, Culicover and Jackendoff 2005, etc.). While most evidence for or against structure in ellipsis concentrates on syntactic issues (e.g. connectivity effects, locality effects, preposition-stranding generalization, etc., cf. Merchant 2001, 2004, 2018), less attention has been paid to other linguistic levels, such as information structure.

The goal of this paper is to examine ellipsis from an information structure perspective, and in particular to observe the specific information structure constraints which are at work in gapping constructions. The paper is structured as follows: In section 2 , we review the literature on the information structure of ellipsis in general, by focusing on the central notions, such as focus, givenness and contrastive topic. In section 3 , we

\footnotetext{
* University of Bucharest and Laboratoire de Linguistique Formelle (Paris), gabriela.bilbiie@gmail.com.

Bucharest Working Papers in Linguistics XXI, 2, 81-100, ISSN 2392-8093, ISSN-L 2069-9239 DOI: 10.31178/BWPL.21.2.4
} 
present the previous approaches on the information structure of gapping and give a discursive perspective on gapping by using a Question under Discussion model. In section 4, we discuss the information structure of gapping in Romanian, by examining a highly frequent pattern, namely gapping with the contrastive conjunction iar 'and'. In order to explain the affinity between iar and the gapping construction, we give some evidence that shows the crucial aspects they have in common. We then examine the specific information structure involved in coordinations with iar, which challenges some of the general assumptions made in the literature. In addition, our results question the strict syntactic parallelism constraint, which is assumed to be at work in contrastive ellipses, such as gapping.

\section{The role of information structure in ellipsis}

The general observation related to the information structure of elliptical constructions comes from the syntax-information structure mapping mostly invoked by structural approaches. One popular view in this kind of accounts is that ellipsis involves a movement operation that is tied to the information structure of the construction (Kim 1997, Depiante 2000, Hartmann 2000, Merchant 2001, 2004, López and Winkler 2003, Winkler 2005, etc.). In particular, it is argued that the material left behind ellipsis (i.e. the remnant) moves leftwards to a position reserved for focus marked constituents (either the edge of the local clause or the edge of the local VP, cf. Rizzi 1997), i.e. syntactic focus movement. Therefore, the remnants are considered to be focus marked, focus movement to the left edge of the clause or the VP creating the elidable string.

Two central notions are worth mentioning from these focus-based approaches postulating a mapping between syntax and information structure of ellipsis. The first one is the notion of focus itself which receives in the literature a non-uniform treatment, being used in various senses ${ }^{1}$. We recall here the broader sense of focus, invoked by Rooth $(1985,1992,1996,2016)$ in alternative semantics. In Rooth's perspective, the general function of focus is to evoke a suitable set of alternatives (relevant for the interpretation of linguistic expressions), from which a subset is chosen. Each linguistic expression has an ordinary semantic value and a "focus semantic value", consisting of a set of alternatives, with a cardinality of at least two elements. Rooth further makes the connection between alternative semantics for focus and alternative semantics for questions. From this perspective, a question is a set of alternative propositions (Hamblin 1973), from where an answer may be chosen. Focus indicates in this case the new information in response to a question: it is the part filling in an open proposition. By relating the notion of focus with the notion of alternatives, one may say that focus is contrastive, it evokes a contrast set $^{2}$. Applied to elliptical phenomena in general, this

\footnotetext{
${ }^{1}$ In the literature on focus, it has been common to draw a sharp division between semantic (Rooth 1985, 1992, 1996) and pragmatic (Krifka 2008) uses of focus. There are also approaches which collapse the distinction between semantic and pragmatic focus (e.g. Roberts 1996/2012, Ginzburg 1996, 2012, Büring 2003, 2016).

${ }^{2}$ The broader sense of focus (from alternative semantics) is usually referred to as contrastive focus (or "contrast" in Vallduví and Vilkuna 1998), while the more pragmatic notion of focus (i.e. new information) is
} 
means that a remnant (i.e. the material left behind ellipsis) in an elliptical sequence is a focus-marked constituent and occurs in a contrastive relationship with a corresponding element (i.e. a correlate) in the non-elliptical counterpart (i.e. the "source" sequence). In other words, the remnant and its correlate have to belong to the same set of alternatives, to the same contrast set, forming a contrastive pair (Molnár and Winkler 2010, Repp 2016, etc.). At the prosodic level, contrastive interpretation of remnants and correlates is associated with prosodic prominence (i.e. accentuation: a high pitch accent on a stressed syllable of a word within a focus constituent). More generally, according to Rooth (1996), focus plays a role in the grammar of ellipsis, facilitating the resolution of ellipsis.

The second notion is that of givenness, giving rise to the so-called e-GIVENness condition (Merchant 2001, 2004, building on Schwarzschild 1999). We recall here the definition given by Winkler (2016: 362), which is related to the original version from Halliday (1967): "A referent or part of a sentence is given if it is anaphoric to a constituent mentioned previously in the discourse, or if it is entailed by the previous discourse" ${ }^{3}$. A general observation which is made in the literature in relation with elliptical phenomena is that the unpronounced material (i.e. the missing material) in the ellipsis site is always given. At the prosodic level, the given material is always deaccented ("distinguished low-flat intonation", cf. Chomsky and Lasnik 1993: 564), which allows its non-pronunciation in the elliptical sequence (Tancredi 1992, Chomsky and Lasnik 1993, etc.).

These two notions (contrastive focus and givenness) have been used to distinguish between two main classes of elliptical constructions, based on two different hypotheses (Winkler 2005, Konietzko and Winkler 2010, Winkler 2016): the "Givenness Marking" Hypothesis (1a) and the "Contrastive Remnant" Hypothesis (1b):

a. Givenness Marking Hypothesis

Given material is deaccented or deleted at Phonological Form.

b. Contrastive Remnant Hypothesis

(Winkler 2016: 363)

Given or redundant information licenses a contrastive interpretation of the remnant(s) with respect to their correlate(s).

(Winkler 2016: 364)

The proponents of these two hypotheses consider that the Givenness Marking Hypothesis holds for what is called "constituent ellipsis" (where the missing material corresponds to a constituent), namely Verb Phrase Ellipsis (VPE), sluicing or nominal ellipsis, while the Contrastive Remnant Hypothesis holds for "non-constituent ellipsis" (where the missing material does not correspond to a regular constituent), namely gapping, stripping or Right Node Raising (RNR). Since the second hypothesis concentrates on the contrastive

given by the notion of informational or presentational focus (for more details about this distinction, see Gundel and Fretheim 2004, Winkler 2005, Krifka 2008, etc.). At this stage, we do not make any distinction between these two terms. We discuss informational focus further in the section 4.2.

${ }^{3}$ See the distinction made by Féry and Ishihara (2016) between text-givenness (in cases where the given material is previously mentioned in the discourse) and context-givenness (in cases where the given material is contextually salient). 
relationship between remnants and correlates, these "non-constituent" ellipsis types have also been called "contrastive" ellipses. We will not go into detail with regard to this distinction, but we will insist (in the following sections) on the contrastiveness requirement in gapping cases.

If information structure notions have been involved in the classification of various elliptical constructions, they have also been used to propose a finer-grained distinction between two subtypes of the same elliptical construction. Kertz (2010, 2013) convincingly shows that there are two subtypes of VPE in English, involving two distinct focus constructions: "auxiliary focus" (2a) vs. "subject focus" (2b). In the first subcase of VPE, one presents an identity between the subject of the antecedent and the subject of the elliptical clause and a focus on the auxiliary (signalling a new choice of tense, aspect, modality or polarity), while in the second subcase of VPE, the focus is on the subject, which is distinct from the subject of the antecedent.

$$
\begin{aligned}
& \text { a. A: He shops in women's. B: No, he DOESN'T. } \\
& \text { b. She shops in women's and HE does too. }
\end{aligned}
$$

Similarly, Konietzko and Winkler (2010) and Winkler (2016) observe two subtypes of stripping (called also Bare Argument Ellipsis) in German, with a different information structure: one in which the remnant functions as a contrastive topic, followed by an accented focus-sensitive particle or negation (CT-ellipsis, as in (3a)), and one in which the remnant functions as a contrastive focus, preceded by a focus-sensitive particle or negation (CF-ellipsis, as in ( $3 b)$ ). Like focus, a contrastive topic relates to alternatives (Büring 2003, 2016) and occurs in "obligatory combination [...] with an additional focus in the sentence" (Mólnar 1998: 135). As it indicates an alternative aboutness topic (Krifka 2008), it corresponds to the constituent which generally occurs in sentence-initial position and receives a rising accent. The presence of an alternative is highlighted, indicating that the present clause does not provide all the information that is expected. We will come back to the notion of contrastive topic in subsequent sections, when we discuss the specific case of gapping.

$$
\begin{aligned}
& \text { a. Sandy spielt FUSSBALL, und TENNIS, AUCH. } \\
& \text { Sandy plays soccer and tennis too } \\
& \text { b. Sandy spielt FUSSBALL, und auch TENNIS. } \\
& \text { Sandy plays soccer, and too tennis } \\
& \text { 'Sandy plays soccer, and tennis, too.' }
\end{aligned}
$$

(Konietzko and Winkler 2010: 1437)

In conclusion, we have seen in this section that, despite the high prevalence of syntactic studies on elliptical constructions, some notions related to information structure aspects have proved to be very helpful in the description and analysis of elliptical constructions. Recent studies go even beyond by assuming that information structure can

\footnotetext{
${ }^{4}$ The word (or the stressed syllable) bearing a high pitch accent (i.e. intonational focus), in relation with focus marking, will be indicated throughout the paper in small caps.
} 
be a good predictor of acceptability for some ellipsis cases with mismatch phenomena. For example, Kertz $(2010,2013)$ convincingly shows, based on experimental evidence, that cases of acceptable and unacceptable mismatch in VPE constructions are characterized by two distinct focus constructions (as mentioned above). We will observe that in gapping, too, apparent syntactic parallelism effects may be explained as a consequence of information structure (and discourse) constraints.

\section{Information structure and discourse aspects in gapping constructions}

In this paper, we concentrate on the gapping construction, which refers to any elliptical clause containing at least two remnants (one of them being generally - but not necessarily - the subject) and lacking at least the main verb (which is generally in medial position in non-head-final languages, such as English or Romance languages). A typical example is given in (4), where the syntactically incomplete clause (= target clause or gapped clause) and Mary bananas is coordinated with the complete clause John bought apples, which provides the material which is necessary for the interpretation (= source clause). The target clause contains the missing material (= gap) and the residual NPs Mary and bananas (= remnants), while the source clause contains the antecedent of the missing material, e.g. the verb bought, and the correlates John and apples, which are parallel to remnants in the target clause. As gapping requires a strong semantic and discourse parallelism (cf. section 4.1), it mostly occurs in coordination structures.

(4) [John bought apples], [and Mary bananas].

\subsection{Previous approaches on information structure of gapping}

Kuno (1976) is the first to observe that the discourse appropriateness of gapping is managed by information structure. According to his Functional Sentence Perspective Principle of gapping, only contextually known (given) elements can be gapped and only contrastive (and therefore new, unpredictable) information can be left behind after ellipsis in the gapped clause. There is a contrastive relation between remnants and correlates; remnants must be paired with correlates in the source clause, so in Kuno's view both remnants and correlates represent new information. These general principles postulated by Kuno (1976) - and captured by Winkler (2016) in (5) - have been frequently adopted in the literature on gapping (Sag 1976, Pesetsky 1982, Kim 1997, Hartmann 2000, Johnson 2014).

(5) Contrastive Remnant Principle

In gapping, remnants must occur in a contrastive relation to their correlates. The deleted elements must be given.

(Winkler 2016: 373)

Based on Kuno (1976)'s classical analysis, Johnson (2014) postulates (along with the syntactic Constituency Condition of Remnants, related to the maximal projection 
requirement on remnants, cf. Hankamer 1973's "Major Constituent" Condition) an information structure constraint on remnants, called Kuno's "Novelty Condition" (6):

\section{Kuno's Novelty Condition on Remnants}

The phrases in the coordinate that are left over from Gapping introduce new information.

(Johnson 2014: 17)

Whereas in the literature on gapping there is a general consensus on the givenness status of the missing material as well as on the contrastive relationship that must exist between remnants and correlates, scholars are divided in their views when it comes to the informational status of remnants: for some of them (Kuno 1976, Hartmann 2000, Johnson 2014), all remnants have a focus contribution; for others (Winkler 2005, 2016, Repp 2009, Konietzko and Winkler 2010), there is a remnant which has a topic contribution. As all of them agree with the contrastiveness requirement (i.e. association with alternatives), the two divides can be summarised as follows: the gapped clause contains only contrastive foci (cf. the first view) or it contains a contrastive topic and a contrastive focus, each remnant having a specific information role (cf. the second view). The lack of consensus on the informational status of remnants may be due to the non-uniform uses of the notion of focus (see the discussion in section 2), and implicitly of the notion of contrastive topic ${ }^{5}$. As discussed by Konietzko and Winkler (2010), there are three different approaches to the notion of contrastive topic: (i) a contrastive topic is a subtype of topic (Kuno 1976, Büring 1997), (ii) a contrastive topic is a focus within a topic (Krifka 1998), or (iii) a contrastive topic is actually a focus (Selkirk 1984). Given this ongoing debate, one needs to be explicit with respect to the notions of contrastive focus and contrastive topic.

As previously mentioned in section 2, a common property that is shared by contrastive foci and contrastive topics is their ability to evoke alternatives (see also Büring 2016). Alternatives from a set have to be of the appropriate type (Rooth 1992), neither of them subsumes one of the others (Zeevat 2004, Umbach 2005), and there must be a semantic opposition between them, these constraints being captured by the "similarity and dissimilarity" relation proposed in the literature (Sag 1976, Rooth 1992, Vallduví and Vilkuna 1998, Umbach 2005). In the case of gapping illustrated below in (7a), one observes that remnants and correlates indeed stand in a contrastive relationship, forming two contrastive pairs: $\{$ John, Mary\} and $\{$ bourbon, scotch $\}$. The elements of each contrastive pair belong to the same domain (same contrast set: individuals and alcoholic drinks, respectively) and at the same time they are different. By contrast, the gapping example in (7b) is unacceptable, since in the second contrastive pair $\{a$ drink, $a$ martini , the remnant is subsumed by its correlate. Same observations on the infelicity of

\footnotetext{
${ }^{5}$ The first type of accounts (multiple contrastive foci) could be also motivated by the mapping syntaxinformation structure of the construction. A general view in mainstream generative grammars is that remnants focus-move to a position outside the ellipsis site. This movement operation is tied to the focus structure of gapping. As one may have more than two remnants in a gapping construction, one has to allow an indefinite number of focus positions to be moved into (Johnson 2018).
} 
the examples in $(7 \mathrm{c}-\mathrm{d})$ : the elements of the second contrastive pair do not belong to the same contrast set or they do not have the same semantic type.

(7) a. John drinks bourbon and Mary scotch.

b. \#John had a drink, and Mary a martini.

c. \#John plays piano and Mary airs of Chopin.

d. \#John eats apples and Mary at midnight.

Coming now to the notion of contrastive topic, we rely on the criteria for topichood used by Winkler (2005) and Konietzko and Winkler (2010): contrastive topics have a specific position, they occur in sentence-initial position; each contrastive topic is cooccurrent with a focus; and they generally have a rising intonation. On the basis of these criteria, the first remnant and correlate are analysed as being contrastive topics, and not foci. The Contrastive Remnant Principle mentioned above in (5) can therefore be refined as in (8):

Contrastive Topic and Contrastive Focus Remnants

In gapping, the first remnant is a contrastive topic, the second remnant a contrastive focus. The gapped elements must be given.

(Winkler 2016: 374)

We have to mention that the two existing approaches (contrastive foci, cf. Kuno 1976 vs. contrastive topic and focus, cf. Winkler 2005) do not base their assumptions on solid empirical investigations. The goal of our paper is to give empirical support in favour of the second analysis (contrastive topic and focus structure), by analysing Romanian gapping with a specific conjunction iar 'and', which is very sensitive to information structure.

A final observation with respect to the previous approaches on information structure of gapping concerns parallelism constraints. Both kinds of accounts assume a parallelism between syntax and information structure, e.g. word order reflects the information structure. Following this perfect match hypothesis between information structure and a parallel syntactic structure (Hartmann 2000, López and Winkler 2003, Winkler 2005, 2016, etc.), one expects to have the same linear order between remnants and correlates (same word order in the source and the gapped clause). Johnson (2018) gives several examples from English, which seem to favour this hypothesis. We observe that gapping cases with the same word order in both conjuncts are grammatical $(9 a-b)$, unlike cases where the order of remnants does not match the order of correlates $(9 c-d)$. Same observations can be made for examples in (10). However, contrary to what is commonly assumed, gapping does not require strong syntactic parallelism (Sag et al. 1985, Abeillé et al. 2014, Bîlbîie 2017), as one can observe in (11), where the order of remnants does not parallel that of their correlates. In section 4, Romanian gapping will allow us to observe that the linear order of remnants is not necessarily the same as the linear order of correlates. Moreover, if one assumes Winkler $(2005,2016)$ 's perspective on the ordering of contrastive topics and foci (i.e. both the source and the target clause have a contrastive topic before a focus element), we will see that one encounters 
problems when one has to account for Romanian gapping, where the pattern can be reversed in the source clause compared to the target clause.

(9) a. Into the study walked Mary and into the closet, Sam.

b. *Into the study walked Mary and Sam, into the closet.

c. Mary walked into the study and Sam, into the closet.

d. *Mary walked into the study and into the closet, Sam.

(10) a. *Some ate beans and rice others. (Johnson 2018)

b. *Some brought pickles for Sam and others for Mary olives.

(11) A policeman walked in at 11, and at 12, a fireman. (Sag et al. 1985: 158)

Before discussing the empirical evidence from Romanian gapping, we will briefly discuss some discursive aspects, which will help us to get a better understanding of gapping.

\subsection{A QUD analysis of gapping}

It is common practice to investigate both information structure and discourse structure by appealing to questions. Question-based approaches to discourse and information structure are known as Question under Discussion (QUD) models (Roberts 1996/2012, Ginzburg and Sag 2000, Ginzburg 2012, Velleman and Beaver 2016, etc.). In these accounts, discourse proceeds by raising and answering implicit (or explicit) questions; every utterance in discourse can thus be related to a current question (QUD). ${ }^{6}$ QUD accounts make use of the question-answer congruence (Rooth 1992) to analyse discourse coherence. The correlation between a question and an answer states that a question must be paired with an appropriate answer. In general, the current question (QUD) is determined by focus, contrastive topic marking and discursive relations. In information structure, questions serve as a diagnostic tool to distinguish between focus and topic. The placement of focus presupposes a particular QUD (Roberts 1996/2012). Focus indicates the new information in response to a question (Büring 2003, 2016).

This QUD perspective, based on question-answer congruence, has been proposed as test for the discursive appropriateness of gapping (Kuno 1976, 1982, Steedman 1990, 2000, Reich 2007, Winkler 2005, 2016, Repp 2009, Johnson 2014): gapping would be felicitous if and only if it can answer a multiple wh-question; the discursive pattern in a gapping construction would be a pair-list answer to an implicit wh-question (12). See, in this respect, the quotation from Steedman (1990: 248): "even the most basic gapped sentence, like Fred ate bread, and Harry, bananas, is only really felicitous in contexts which support (or can accommodate) the presupposition that the topic under discussion is Who ate what."

Q: Who ate what?

A: Fred ate bread, and Harry bananas.

${ }^{6}$ The (overt or covert) questions in a discourse form a hierarchical discourse structure (i.e. a big question divided then into sub-questions), cf. Büring (2003)'s "discourse-tree". 
More complicated gapping cases, e.g. with more than two remnants, which are considered as less acceptable or even ungrammatical, improve if they can be interpreted as answers to a specific question. We can have thus an explanation for apparent contradictory data, as discussed by Johnson (2014). In the absence of an appropriate wh-question, the gapping example with three remnants in (13a) seems to be ungrammatical in English, leading some scholars to postulate that in gapping there may be no more than two remnants (Jackendoff 1971). However, Johnson (2014) observes that a similar example is quite acceptable in the presence of a multiple wh-question, as in (13b). A number of other so-called syntactic constraints could be explained by a QUD account of gapping, e.g. the fact that voice mismatches (14a) or tense mismatches (14b) are unavailable in gapping: with these syntactic mismatches, there is a QUD mismatch between the source and the gapped clause, they do not answer the same wh-question?

(13) a. *Millie will send the President an obscene telegram, Paul the Queen a pregnant duck. (Jackendoff 1971: 25)

b. Q: Who will send who what?

A: Sally will send Ron pickles, and Martha Hermione kumquats.

(14) a. *Lilies are brought by some and others roses.

(Johnson 2014)

b. *John went yesterday to the movies, and Mary tomorrow to the pool.

If one assumes that gapping is the elliptical version of a pair-list answer to a multiple wh-question, the question-answer congruence would allow us to observe the information structure role that each remnant has in a gapped clause. According to Büring (2016), answers to a multiple wh-question (15a) or a single wh-question containing plurals $(15 \mathrm{~b})$ typically allow a contrastive topic + focus $(\mathrm{CT}+\mathrm{F})$ configuration. We have now more arguments in favour of the analysis proposed by Winkler $(2005,2016)$, Repp (2009), Konietzko and Winkler (2010), who admit that the information structure of both conjuncts in a gapping construction would contain a contrastive topic followed by a contrastive focus. A contrastive topic relation is well formed if members of the topic set are sentence topics, i.e. they have already been mentioned or are salient in the discourse.

(15) a. Q: Which guest brought what?

A: John brought fruit juice and Cesar alcoholic drinks.

b. Q: What drinks did the two guests bring?

A: John brought fruit juice and Cesar alcoholic drinks.

A marginal question arising at this point is which conjunct serves as basis for the reconstruction of a wh-QUD: the source or the target? Two answers can be given: (i) if

\footnotetext{
${ }^{7}$ See also the so-called No Embedding Constraint (Johnson 2014) which does not allow the gapped clause to be embedded within the conjunct to which it belongs: Bîlbîie and de la Fuente (2019) observe that some languages (such as Spanish) accept embedded gapping with non-factive verbs, but less with factive verbs; the explanation is related to a QUD match/mismatch rather than to a syntactic constraint: in embedded gapping with non-factive verbs, as in regular gapping cases, both the source and the target address the same QUD, unlike in embedded gapping with factive verbs where the conjuncts address different QUDs.
} 
one follows Reich (2007), the most salient wh-QUD is reconstructed on the basis of the information structure of the initial conjunct (the source clause); (ii) if one follows Schwabe (2000), it is the second conjunct (the target) that determines the information structure of the first one: "It is the second conjunct in particular that gives insights into the syntactic, semantic and information structure of its antecedent. [...] the information structure of the second conjunct determines the information structure and thus the syntax and semantics of the first" (Schwabe 2000: 247).

Our empirical data on Romanian gapping will bring solid evidence in favour of a contrastive topic + focus pattern and, at the same time, will show the importance of the second clause (the target) for determining the information structure of the whole construction.

\section{Romanian gapping with iar}

Romanian has a specific clausal coordinator iar, which is the most frequent conjunction in elliptical coordinations, in particular in gapping constructions (Bîlbîie 2017). Romanian distinguishes itself from other Romance languages by having a special "contrastive" conjunction iar (16a), similar to the conjunction a (16b) in several Slavic languages (Jasinskaja and Zeevat 2009, Repp 2009), with an "intermediate" meaning between the additive and the adversative connectors, as illustrated in Table 1 (for a comparison between them, see Bîlbîie and Winterstein 2011).

a. Ion adoră fotbalul, iar Maria baschetul. (Romanian)

'Ion likes football, and Maria basketball.'

b. Oleg ljubit futbol, a Maria basketbol. (Russian)

'Oleg likes football, and Maria basketball.'

Table 1: Conjunction space in four languages

\begin{tabular}{|c|c|c|c|}
\hline French & Spanish & Romanian & Russian \\
\hline et & & şi & $i$ \\
\hline & pero & iar & $a$ \\
\hline \multirow[t]{2}{*}{ mais } & & $d a r$ & no \\
\hline & $\operatorname{sino}$ & $c i$ & $a$ \\
\hline
\end{tabular}

In most contexts with gapping, the contrastive iar stands in a free distribution with the additive conjunction şi 'and', as illustrated in (17), though a closer look at the data shows a strong preference for using iar instead of şi. Whereas the additive şi is underspecified, being compatible with both subclausal and clausal coordination, the contrastive iar obeys some very specific requirements (Bîlbîie and Winterstein 2011). The goal of the following subsections is to explain the affinity between the conjunction iar and gapping, by showing the specific constraints of this conjunction, which make it 
unique in the Romanian conjunction space. Particular attention is devoted to the specific constraints on the information structure of the second conjunct in a iar coordination.

(17) Alice studiază la Paris, \{iar / şi $\}$ Maria la Londra.

'Alice studies in Paris, and Maria in London.'

\subsection{Explaining the affinity between iar and gapping}

The natural question arising from the high frequency of the conjunction iar in Romanian gapping constructions is where this affinity between iar and gapping comes from. A closer look into the specific constraints of iar in general and into the constraints imposed by gapping (with and without iar) crucially allows us to observe an overlap between the constraints imposed by iar and gapping.

First of all, a major requirement on conjuncts introduced by iar is that they must contain at least two contrastive pairs ("double contrastiveness constraint"), as illustrated in (18b). If there is only one contrastive pair, as in (18a), the conjunction iar is excluded, the only possibility being the use of its counterpart şi. As discussed in section 3.1 above, the gapping construction is characterized by exactly the same constraint: there must be at least two contrastive pairs, i.e. a semantic contrast between remnants and correlates (Sag 1976, Hartmann 2000, Repp 2009, etc). A contrastive pair is explicited by a "similarity and dissimilarity" relation, defined by two aspects (Zeevat 2004, Umbach 2005): (i) its elements must belong to the same set of alternatives (same contrast set), and simultaneously (ii) they must be different (there must be a semantic opposition between them). This explains the infelicity of examples in (18c-d), where one of the two contrastive pairs has a non-contrastive nature, the nominal sportul subsuming the nominal baschetul (18c) or fotbalul (18d).

a. Ion adoră fotbalul $\{*$ iar / şi $\}$ baschetul. 'Ion likes football and basketball.'

b. Ion adoră fotbalul, iar *(Maria) (adoră) baschetul. 'Ion likes football, and Maria (likes) basketball.'

c. \#Ion adoră sportul, iar Maria (adoră) baschetul. 'Ion likes sport, and Maria (likes) basketball.'

d. $\quad$ \#Ion adoră fotbalul, iar Maria (adoră) sportul. 'Ion likes football, and Maria (likes) sport.'

Furthermore, as we will see in 4.2 , the contrastive pairs linked by iar provide the answers to an implicit wh-question: either a multiple wh-question (19a) or a single wh-question containing plurals (19b). This question-answer congruence will serve us as a diagnostic tool to investigate the information structure of coordination with iar. In 3.2 above, we observed the exact same pattern: gapping is appropriate in contexts where the sequence is interpreted as a pair-list answer to an implicit wh-question (Kuno 1976, 1982, Steedman 1990, 2000, Reich 2007, Winkler 2005, 2016, Repp 2009, Johnson 2014). 
(19) a. Q: Cine (și) ce a adus la petrecere?

'Who brought what to the party?'

A: Maria a adus desertul, iar Ion (a adus) băutura.

'Maria brought the dessert, and Ion (brought) the drinks.'

b. Q: Ce băuturi au adus cei doi invitați?

'What drinks did the two guests bring?'

A: Maria a adus suc de fructe, iar Ion (a adus) băuturi alcoolice.

'Maria brought fruit juice, and Ion (brought) alcoholic drinks.'

Third, the conjunction iar is only felicitous with symmetric discourse relations. These relations are called resemblance relations (Kehler 2000, 2002), parallel relations (Asher and Lascarides 2003) or similar relations (Repp 2016). With symmetric discourse relations, there is "a common relation $p$ that applies over a set of entities $a_{1}, \ldots, a_{\mathrm{n}}$ from the first sentence and a set of entities $b_{1}, \ldots, b_{\mathrm{n}}$ from the second sentence, and performs comparison and generalization operations on each pair of parallel elements" (Kehler 2000: 544). This means that the conjuncts must make the same contribution to the current question under discussion, based on the 'similarity and dissimilarity' relation discussed above: one establishes similarities and contrasts between corresponding sets of entities or events. Consequently, a symmetric discourse relation is preserved when the order of the conjuncts is reversed (20a-b), without changing the truth conditions of the sentence. As indicated by Kehler (2000), the prototypical case of a symmetric discourse relation is parallelism; thus, it is not surprising that the conjunction iar occurs in such discursive environments. As for gapping, Levin and Prince (1986) and Kehler (2002) observed the same constraint: gapping is only compatible with symmetric discourse relations, such as parallelism (21a) or contrast (21b), while it is excluded with cause-effect relations, such as concession, consequence or condition.

(20) a. $\quad$ Ion preferă să se uite la un film, iar Maria (preferă) să meargă la cumpărături.

'Ion prefers to watch a movie, and Maria (prefers) to go shopping.'

b. Maria preferă să meargă la cumpărături, iar Ion (preferă) să se uite la un film.

'Maria prefers to go shopping, and Ion (prefers) to watch a movie.'

(21) a. Cei doi soţi învaţă fiecare câte o limbă străină. Ion învaţă germana, iar Maria (învaţă) franceza.

'Each spouse learns a foreign language. Ion learns German, and Maria (learns) French.'

b. Cei doi soţi au vederi politice diferite. Ion va vota cu PSD, iar Maria (va vota) cu USR.

'The two spouses have different political views. Ion will vote for PSD, and Maria (will vote) for USR.'

Fourth, at syntactic level, the conjunction iar only coordinates clausal constituents, and the two contrastive pairs have to be maximal projections. This explains why the conjunction iar cannot be used in (22), where only the conjunction şi is available: 
although one can get a contrast between two kinds of fruits <mere, pere $>$ and two different colors <verzi, galbene $>$, the two contrastive pairs are contained in the same nominal phrase. Therefore, the conjuncts linked by iar have to be clauses (finite clauses or elliptical clauses with a propositional content). Coming back to gapping, it is restricted by definition to occur in a multi-clausal context, since it coordinates a full clause with an elliptical one (which contains in most cases a subject as remnant).

Ioana mănâncă mere verzi $\left\{*^{i}\right.$ iar / şi $\}$ pere galbene.

'Ioana eats green apples, and yellow pears.'

To summarise, we have observed that the affinity between Romanian gapping and the conjunction iar is not at all surprising. The high frequency of iar in these elliptical contexts is due to the fact that it shares many of the specific constraints imposed by gapping constructions: both require conjuncts with at least two contrastive pairs, both are appropriate and natural in an answer to a multiple $w h$-question, both are only compatible with symmetric discourse relations (in particular, parallelism and contrast), and both apply only at the clausal level.

\subsection{The information structure of iar constructions}

In the previous section, we gave some explanations for the speakers' preference to use the conjunction iar in gapping, by listing some specific constraints that are shared by iar and the gapping construction. The last issue which remains to be discussed concerns the information structure constraints imposed by the conjunction iar in Romanian. This discussion will allow us to have a finer-grained perspective on the role that each element of a contrastive pair has in terms of information structure. In particular, it will help us to choose between the two existing approaches on the information structure of gapping: (i) all contrastive pairs are foci (i.e. new information, cf. Kuno's Novelty Condition proposed by Johnson 2014) or (ii) the first contrastive pair contains contrastive topics, whereas the other contains foci (Winkler 2005, 2016, Konietzko and Winkler 2010). In addition, the investigation of iar constructions will enable us to observe which conjunct (the source or the target) decides the information structure of the whole construction and serves as basis for the reconstruction of a $w h$-QUD.

In order to test the information structure of a sequence with iar, we will make use of the classical diagnostic tool to distinguish between focus and topic, namey the use of a QUD model based on the question-answer congruence. By using an overt question, we can make explicit the informational structure of an utterance. As mentioned in 3.2, every utterance in discourse can be related to an appropriate question. In the case at stake, the contrastive pairs linked by iar provide the answers to an implicit wh-question: either a multiple $w h$-question or a single $w h$-question containing plurals (see the examples (19a-b) and (23)-(24)).

Crucially, the QUD analysis of the coordination with iar shows us that the contribution of the contrastive pairs in terms of information structure is not identical. In particular, the conjunction iar imposes a certain ordering in the second conjunct, with a specific information structure. Though Romanian has a relatively free word order, in the 
absence of a specific intonation, the preferred placement of the element that answers the question is at the end of the conjunct, whereas the element already present in the question (underlined in the examples below) appears right after the conjunction iar. If one compares (23) and (24), the main difference consists of the relative order of individuals (Ioana, Maria) and locations (la film, la teatru), depending on the asked question. The information which is already given in the question will necessarily precede the new information.

(23) Q: Cu cine vei merge la film şi cu cine la teatru?

'With whom will you go to the movies and with whom to the play?'

a. $\quad$ La film voi merge cu Ioana, iar la teatru cu Maria.

'To the movies I will go with Ioana, and to the play with Maria.'

b. $\quad$ \#Cu Ioana voi merge la film, iar cu Maria la teatru.

'With Ioana I will go to the movies, and with Maria to the play.'

(24) Q: Unde ieşi cu fetele weekendul ăsta?

'Where will you go out with your daughters this weekend?'

a. $\quad \mathrm{Cu}$ Ioana voi merge la film, iar cu Maria la teatru.

'With Ioana I will go to the movies, and with Maria to the play.'

b. $\quad$ \#La film voi merge cu Ioana, iar la teatru cu Maria.

'To the movies I will go with Ioana, and to the play with Maria.'

In order to account for this ordering imposed by the information structure, we make use of the notions of contrastive topic and informational focus, related to those defined in Büring (2003): informational foci are the constituents that answer a question (and in many cases, they are marked by a specific prosodic contour); contrastive topics are elements that have already been mentioned or are salient in the discourse (the notion of contrastive topic corresponds to the notion of 'sorting key' proposed by Kuno 1982: it is the element which gives an indication about the way one has to answer the question); it normally creates an independent Intonational Phrase. A preliminary conclusion that one can draw from the examples above is that the first contrastive pair in a coordination with iar has the status of contrastive topic, whereas the second one has the status of informational focus.

In order to further assess the information structure behaviour of the contrastive pairs coordinated by iar, we use three specific tests which force the identification of the informational focus: (i) variation in the placement of the prosodic stress (i.e. intonational focus), (ii) variation between indefinite and definite nominal phrases, and (iii) use of the so-called focus sensitive particles.

By applying the first test to our coordinations with iar, namely the emphatic realization of the lexical accent (prosodic stress marking the intonational focus, which is indicated by small caps in (25)-(26)), we easily observe that the first element following iar cannot bear a prosodic stress (i.e. it cannot be an informational focus), as illustrated in (25b) and (26b). We obtain the same acceptability judgments as in (23)-(24) above. An interesting point concerns the lack of strict syntactic parallelism between the two conjuncts. While in the second conjunct introduced by the conjunction iar the order of elements is rigid (i.e. the contrastive topic is always the first constituent and the 
informational focus follows it), in the first conjunct the position of the informational focus is not constrained: it can follow the contrastive topic and match the order of the second conjunct as in (25a) and (26a), but it can also be the initial constituent in the clause, as in (25c) and (26c). Therefore, there is no need to postulate a strict syntactic parallelism between the source and the clause (contra Winkler 2005, 2016, Konietzko and Winkler 2010): the order of elements in the first conjunct may be different from the order of elements in the conjunct introduced by iar, the last one being constrained to have a very rigid order.

(25) Q: Cu cine vei merge la film şi cu cine la teatru?

'With whom will you go to the movies and with whom to the play?'

a. $\quad$ La film voi merge cu IOAna, iar la teatru cu MaRIA.

'To the movies I will go with Ioana, and to the play with Maria.'

b. $\quad$ \#Cu IOAna voi merge la film, iar cu MaRIA la teatru.

'With Ioana I will go to the movies, and with Maria to the play.'

c. $\quad \mathrm{Cu}$ IOAna merg la film, iar la teatru cu MaRIA.

'With Ioana I will go to the movies, and to the play with Maria.'

Q: Unde ieşi cu fetele weekendul ăsta?

'Where will you go out with your daughters this weekend?'

a. $\quad \mathrm{Cu}$ Ioana voi merge la FILM, iar cu Maria la TEAtru.

'With Ioana I will go to the movies, and with Maria to the play.'

b. \#La FILM voi merge cu Ioana, iar la TEAtru cu Maria.

'To the movies I will go with Ioana, and to the play with Maria.'

c. La FILM voi merge cu Ioana, iar cu Maria la TEAtru.

The second test allowing us to observe the topic/focus partition in the conjunct introduced by iar is the (in)definiteness of nominal expressions, building on the wellknown association of topics with definiteness across languages. It is usually assumed that a definite NP signals that the referent is known or identifiable in the discourse (it is construed as part of the background of the utterance), whereas an indefinite NP usually means that the referent is new or it is not identifiable in the discourse (Van Valin and LaPolla 1997). Based on these assumptions, we expect that the first constituent after iar will be a definite rather than an indefinite NP. The examples in (27) confirm these observations: an indefinite NP cannot be the first constituent (27a); if it has been already introduced in the discourse, it will necessarily take a definite determiner (27b). The apparent exceptions are indefinite NPs with a generic interpretation (28). This is not surprising: in languages which have a topic-marking morpheme, such as Japanese or Korean, it has been noted (Kuno 1972, Kuroda 1972) that the topic-marked constituent necessarily has a definite interpretation, including generic cases. Indefinites are not generally used to refer to familiar entities, unless they are interpreted generically, and in this latter case, the "referents of generics would always be familiar, or at least uniquely identifiable, since the addressee could be assumed to have a representation of the class/kind if he knows the meanings of the words in the phrase" (Gundel and Fretheim 2004: 193). Therefore, generic indefinites have a definite interpretation, which allows them to function as topics. 
(27) Q: Cine vrea un măr și cine o pară?

'Who wants an apple and who a pear?'
a. \#Un măr vrea Ion, iar o pară Maria.
an apple wants Ion and a pear Maria
'It is John who wants an apple, and it is Maria who wants a pear.'
b. Mărul îl vrea Ion, iar para Maria. apple-DEF CL.ACC wants Ion and pear-DEF Maria
'It is John who wants the apple, and it is Maria who wants the pear.'

(28) O pară are cam 4,4 grame de fibre, iar un măr cam 3,3.

'A pear has around 4,4 grams of fibre, and an apple around 3,3.'

The third test observes the behaviour of expressions which display a focus sensitivity, namely the so-called focus sensitive particles. An expression is focus sensitive if its interpretation correlates with the location of focus. It is generally assumed that all focus sensitive particles are sensitive to the same thing, e.g. intonational focus (Aloni et al. 1999, Beaver and Clark 2002). We expect that the first constituent after iar in Romanian could not be modified by such associative elements. This is exactly we observe in (29): the first constituent after iar cannot be modified by associative adverbs such as the adverbial şi ' 'too' (29a) or nici 'neither' (29b), having narrow scope on their associate, which usually is an informational focus in the discourse. In these cases, only the conjunction şi is available.

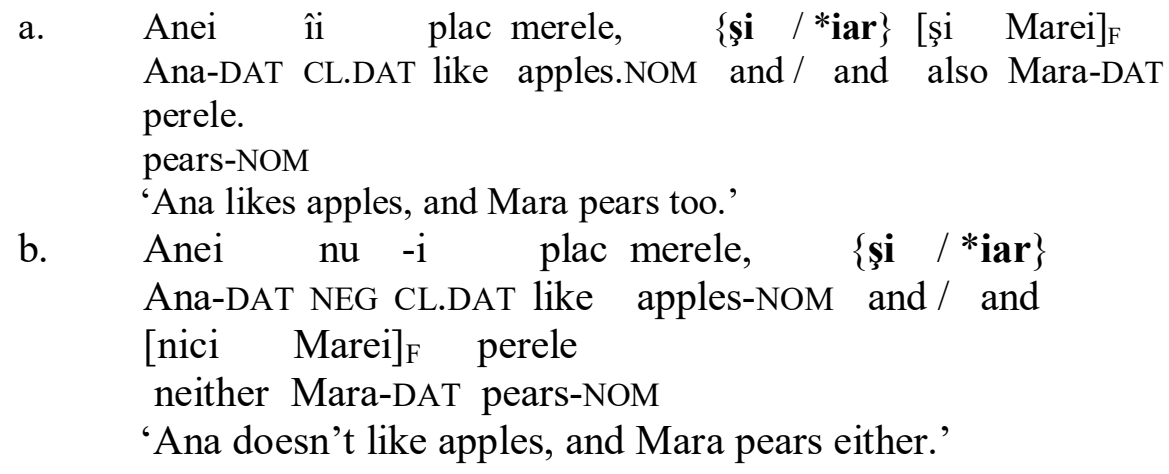

On the basis of this empirical evidence, one can say that Romanian has a topicmarking conjunction, that requires a strict information structure ordering in the second conjunct: iar must be immediately followed by a contrastive topic, which always precedes the informational focus. We can thus say that in gapping constructions with iar the first remnant is always a contrastive topic. This conforms with the criteria for topichood used by Winkler (2005) and Konietzko and Winkler (2010): the contrastive topic after iar has a specific position, it occurs in sentence-initial position (just after iar), and it is co-occurrent with a focus.

\footnotetext{
${ }^{8}$ Note that in Romanian there are two homonym words şi: adverbial şi 'too/also' vs. conjunction şi 'and'.
} 
An additional note of interest in relation with the contrastive topic and focus ordering concerns the cases of gapping with prodrop. In a comparative experimental study, Bîlbîie and de la Fuente (in press) show that gapping with prodrop (30a) is as acceptable as without prodrop (30b), challenging the double foci analysis and supporting the topic-focus pattern. By omitting overt subjects, speakers manifest preference for not spelling out given information (Alonso-Ovalle et al. 2002, Biezma 2014). Therefore, the prodrop subject in the source clause in (30a) is necessarily a topic. This finding is consistent with the assumption that gapping involves a contrastive topic pair along with a focus pair.

(30) Context: Ne-am făcut deja planul pentru weekend.

'We have already planned our weekend.'

a. Voi merge la film, iar sora mea la muzeu

will.1SG go to film and sister-DEF POSS.1SG to museum

'I will go to the cinema, and my sister to the museum.'

b. Eu voi merge la film, iar sora mea la muzeu

I will.1SG go to film and sister-DEF POSS-1SG to museum

'I will go to the cinema, and my sister to the museum.'

To conclude this section, our data go against Kuno's Novelty Condition proposed by Johnson (2014) as a diagnostic criterion for gapping, and assess the heterogeneous behaviour of contrastive pairs, invoked by Winkler $(2005,2016)$ and Konietzko and Winkler (2010): the contrastive pairs in a gapping construction with iar do not have the same information structure status; one pair contains contrastive topics, whereas the other contrastive foci. However, contrary to what these scholars assume, gapping does not require strong syntactic parallelism, since in Romanian the order of remnants does not necessarily parallel that of their correlates. We follow Jackendoff (1972) in assuming that the pattern can be reversed in the source clause, i.e. with focus followed by contrastive topic. Moreover, the specific constraints imposed by iar in the second conjunct require us to reassess the assumption made by Reich (2007), who considers that the source clause serves as basis for the reconstruction of an appropriate $w h$-QUD. This reconstruction has to pay specific attention to the information structure of the target clause introduced by iar.

\section{Conclusions}

The main goal of this paper was to observe the behaviour of ellipsis (in particular, gapping) with respect to information structure, a linguistic level which has been much less studied than syntax or semantics. Romanian is a good test case that allows for an exhaustive analysis of information structure in this kind of constructions, since it displays a specific contrastive conjunction iar 'and', which severely restricts the information structure ordering in the conjunct it introduces. As the conjunction iar is extensively used in gapping constructions, studying this conjunction allows us to cover a wide range of data with gapping. 
The affinity between iar and gapping comes from the overlap we observed between the constraints imposed by iar in general and the constraints imposed by gapping (with and without iar). They share several crucial aspects: both require conjuncts with at least two contrastive pairs, both are appropriate and natural in an answer to a multiple whquestion, both are only compatible with symmetric discourse relations (in particular, parallelism and contrast), and both apply only at the clausal level.

Concerning the information structure itself, our empirical findings show that the contrastive pairs with iar do not have the same contribution: one pair contains contrastive topics, while the other contains foci. This supports Winkler $(2005,2016)$ 's view: the first remnant is a contrastive topic, and the second one a contrastive focus. However, our data show that there is no strict syntactic parallelism between the source and the gapped clause (contra Winkler 2005, 2016, Konietzko and Winkler 2010): the word order of the correlates in the source clause does not necessarily match the rigid order of the remnants in the gapped clause; therefore, whereas in the target clause introduced by iar the contrastive topic has to be the first constituent, in the source clause it can be either before or after the focus element (in this latter case, the focus constituent bears a specific prosodic stress). This shows the importance of the target clause for determining the information structure of the whole construction.

In terms of methodology, it is worth mentioning that the QUD model, based on question-answer congruence, has been a very useful diagnostic tool, which allowed us to obtain a finer-grained perspective on gapping constructions. It is not surprising that many scholars propose a formal analysis in terms of QUD (e.g. Reich 2007, Park 2016) rather than a syntactic-based analysis.

Overall, our investigation supports the statement made by Johnson (2018): “a more careful investigation of the discourse and information structure of Stripping and Gapping seems likely to reduce the number of open mysteries these interesting constructions harbor. I recommend this direction to those embarking on a Gapping and Stripping career."

\section{References}

Abeillé, A., Bîlbîie, G. and Mouret, F. 2014. A Romance perspective on gapping constructions. In H. Boas and F. Gonzálvez-García (eds.), Romance Perspectives on Construction Grammar, 227-267. Amsterdam/Philadelphia: John Benjamins.

Aloni, M., Beaver, D. and Clark, B. 1999. Focus and topic sensitive operators. In P. Dekker (ed.), Proceedings of the 12th Amsterdam Colloquium, 55-60. Amsterdam: ILLC/Department of Philosophy.

Alonso-Ovalle, L., Fernández-Solera, S., Frazier, L. and Clifton, C. 2002. Null vs. overt pronouns and the topic-focus articulation in Spanish. Journal of Italian Linguistics 14 (2): 151-169.

Asher, N. and Lascarides, A. 2003. Logics of Conversation. Cambridge: Cambridge University Press.

Beaver, D. and Clark, B. 2002. The Proper Treatments of Focus Sensitivity. In L. Mikkelsen and C. Potts (eds.), Proceedings of the $21^{\text {st }}$ West Coast Conference on Formal Linguistics, 15-28. Somerville, MA: Cascadilla Press.

Biezma, M. 2014. Multiple focus strategies in pro-drop languages: Evidence from ellipsis in Spanish. Syntax 17 (2): 91-131.

Bîlbîie, G. 2017. Grammaire des constructions elliptiques: Une étude comparative des phrases sans verbe en roumain et en français. Berlin: Language Science Press.

Bîlbîie, G. and Winterstein, G. 2011. Expressing contrast in Romanian: The conjunction iar. In J. Berns, H. Jacobs and T. Scheer (eds.), Romance Languages and Linguistic Theory 2009: Selected Papers from 'Going Romance’ Nice 2009, 1-18. Amsterdam/Philadelphia: John Benjamins. 
Bîlbîie, G. and de la Fuente, I. 2019. Can gapping be embedded? Experimental evidence from Spanish. Glossa: A Journal of General Linguistics 4 (1). http://doi.org/10.5334/gjgl.782.

Bîlbîie, G. and de la Fuente, I. in press. An experimental approach to syntactic parallelism in ellipsis: The case of prodrop in Romance Gapping. In Romance Languages and Linguistic Theory: Selected Papers from 'Going Romance' 31, Bucharest. Amsterdam/Philadelphia: John Benjamins.

Büring, D. 1997. The Meaning of Topic and Focus - The $59^{\text {th }}$ Street Bridge Accent. London: Routledge.

Büring, D. 2003. On D-trees, beans, and B-accents. Linguistics and Philosophy 26: 511-545.

Büring, D. 2016. (Contrastive) Topic. In C. Féry and S. Ishihara (eds.), The Oxford Handbook of Information Structure, 64-85. Oxford University Press.

Chomsky, N. and Lasnik, H. 1993. The theory of principles and parameters. In J. Jacobs, A. von Stechow, W. Sternefeld and T. Vennemann (eds.), Syntax: An International Handbook of Contemporary Research, 506-569. Berlin · New York: Mouton de Gruyter.

Culicover, P. and Jackendoff, R. 2005. Simpler Syntax. Oxford: Oxford University Press.

Dalrymple, M., Shieber, S. and Pereira, F. 1991. Ellipsis and Higher-Order Unification. Linguistics and Philosophy 14 (4): 399-452.

Depiante, M. 2000. The Syntax of Deep and Surface Anaphora: A Study of Null Complement Anaphora and Stripping/Bare Argument Ellipsis. PhD dissertation, University of Connecticut.

Féry, C. and Ishihara, S. 2016. Introduction. In C. Féry and S. Ishihara (eds.), The Oxford Handbook of Information Structure, 1-15. Oxford University Press.

Ginzburg, J. 1996. Interrogatives: Questions, facts and dialogue. In S. Lappin (ed.), The Handbook of Contemporary Semantic Theory, 385-422. Oxford: Blackwell.

Ginzburg, J. 2012. The Interactive Stance: Meaning for Conversation. Oxford: Oxford University Press.

Ginzburg, J. and Sag, I. A. 2000. Interrogative Investigations: The Form, Meaning and Use of English Interrogatives. Stanford, CA: CSLI Publications.

Gundel, J. and Fretheim, T. 2004. Topic and Focus. In L. Horn and G. Ward (eds.), The Handbook of Pragmatic Theory, 174-196. Oxford: Blackwell.

Halliday, M. 1967. Notes on transitivity and theme in English. Part II. Journal of Linguistics 3: 199-244.

Hamblin, C. L. 1973. Questions in Montague English. Foundations of Language 10 (1): 41-53.

Hankamer, J. 1971. Constraints on Deletion in Syntax. PhD dissertation, Yale University.

Hankamer, J. 1973. Unacceptable ambiguity. Linguistic Inquiry 4 (1): 17-68.

Hartmann, K. 2000. Right Node Raising and Gapping. Interface Conditions on Prosodic Deletion. Amsterdam/Philadelphia: John Benjamins.

Jackendoff, R. 1971. Gapping and related rules. Linguistic Inquiry 2 (1): 21-35.

Jackendoff, R. 1972. Semantic Interpretation in Generative Grammar. Cambridge, MA: MIT Press.

Jasinskaja, K. and Zeevat, H. 2009. Explaining conjunction systems: Russian, English, German. In A. Riester and T. Solstad (eds.), Proceedings of Sinn und Bedeutung 13. Stuttgart: University of Stuttgart.

Johnson, K. 2014. Gapping. Ms. University of Massachusetts, Amherst.

Johnson, K. 2018. Gapping and stripping. In J. van Craenenbroeck and T. Temmerman (eds.), The Oxford Handbook of Ellipsis, 563-604. Oxford: Oxford University Press.

Kehler, A. 2000. Coherence and the resolution of ellipsis. Linguistics and Philosophy 23: 533-575.

Kehler, A. 2002. Coherence, Reference and the Theory of Grammar. Stanford, CA: CSLI Publications.

Kertz, L. 2010. Ellipsis Reconsidered. PhD dissertation, University of California at San Diego.

Kertz, L. 2013. Verb phrase ellipsis: The view from information structure. Language 89: 390-428.

Kim, J.-S. 1997. Syntactic Focus Movement and Ellipsis: A Minimalist Approach. PhD dissertation, University of Connecticut.

Konietzko, A. and Winkler, S. 2010. Contrastive ellipsis: Mapping between syntax and information structure. Lingua 120: 1436-1457.

Krifka, M. 2008. Basic notions of information structure. Acta Linguistica Hungarica 55 (3-4): 243-276.

Kuno, S. 1972. Functional Sentence Perspective: A case study from Japanese and English. Linguistic Inquiry 3 (3): 269-320.

Kuno, S. 1976. Gapping: A functional analysis. Linguistic Inquiry 7 (2): 300-318.

Kuno, S. 1982. The focus of the question and the focus of the answer. In R. Schneider, K. Tuite and R. Chametzky (eds.), Chicago Linguistic Society 18, vol. 2, Papers from the Parasession on Nondeclaratives, 134-157. Chicago, IL: Chicago Linguistic Society.

Kuroda, S. Y. 1972. The categorical and the thetic judgement: Evidence from Japanese syntax. Foundations of Language 9: 153-185. 
Levin, N. and Prince, E. 1986. Gapping and Causal Implicature. Papers in Linguistics 19: 351-364.

López, L. and Winkler, S. 2003. Variation at the syntax-semantics interface: Evidence from gapping. In K. Schwabe and S. Winkler (eds.), The Interfaces: Deriving and Interpreting Omitted Structures, 227248. Amsterdam/Philadelphia: John Benjamins.

Merchant, J. 2001. The Syntax of Silence: Sluicing, Islands, and the Theory of Ellipsis. Oxford: Oxford University Press.

Merchant, J. 2004. Fragments and ellipsis. Linguistics and Philosophy 27 (6): 661-738.

Merchant, J. 2018. Ellipsis: A survey of analytical approaches. In J. van Craenenbroeck and T. Temmerman (eds.), The Oxford Handbook of Ellipsis, 19-45. Oxford University Press.

Molnár, V. 1998. Topic in Focus. Acta Linguistica Hungarica 45: 89-166.

Molnár, V. and Winkler, S. 2010. Edges and gaps: The role of contrast in the theory of grammar. Lingua 120: 1392-1415.

Park, S.-H. 2016. Towards a QUD-Based Analysis of Gapping Constructions. In Proceedings of the $30^{\text {th }}$ Pacific Asia Conference on Language, Information and Computation (PACLIC 30), 297-305. https://www.aclweb.org/anthology/Y16-2028.

Pesetsky, D. 1982. Paths and Categories. PhD dissertation, MIT.

Reich, I. 2007. Toward a uniform analysis of short answers and gapping. In K. Schwabe and S. Winkler (eds.), On Information Structure, Meaning and Form, 467-484. Amsterdam/Philadelphia: John Benjamins.

Repp, S. 2009. Negation in Gapping. Oxford University Press.

Repp, S. 2016. Contrast: Dissecting an elusive information-structural notion and its role in grammar. In C. Féry and S. Ishihara (eds.), The Oxford Handbook of Information Structure, 270-290. Oxford University Press.

Rizzi, L. 1997. The fine structure of the left periphery. In L. Haegeman (ed.), Elements of Grammar, 281-337. Dordrecht: Springer.

Roberts, C. 1996/2012. Information structure in discourse: Towards an integrated formal theory of pragmatics. Semantics and Pragmatics 5 (6): 1-69.

Rooth, M. 1985. Association with Focus. PhD dissertation, University of Massachusetts, Amherst.

Rooth, M. 1992. A theory of focus interpretation. Natural Language Semantics 1: 75-116.

Rooth, M. 1996. Focus. In S. Lappin (ed.), Handbook of Contemporary Semantic Theory, 271-297. Oxford: Blackwell.

Rooth, M. 2016. Alternative semantics. In C. Féry and S. Ishihara (eds.), The Oxford Handbook of Information Structure, 128-146. Oxford: Oxford University Press.

Ross, J. R. 1967. Constraints on Variables in Syntax. PhD dissertation, Indiana University.

Sag, I. A. 1976. Deletion and Logical Form. PhD dissertation, MIT.

Sag, I. A., Gazdar, G., Wasow, T and Weisler, S. 1985. Coordination and how to distinguish categories. Natural Language and Linguistic Theory 3: 117-171.

Schwabe, K. 2015. Coordinate ellipsis and information structure. In K. Schwabe and N. Zhang (eds.), Ellipsis in Conjunction, 247-269. Tübingen: Max Niemeyer Verlag.

Schwarzschild, R. 1999. GIVENness, avoidF and other constraints on the placement of focus. Natural Language Semantics 7 (2): 141-177.

Selkirk, E. 1984. Phonology and Syntax: The Relation between Sound and Structure. Cambridge, MA: MIT Press.

Steedman, M. 1990. Gapping as constituent coordination. Linguistics and Philosophy 13 (2): 207-263.

Steedman, M. 2000. The Syntactic Process. Cambridge, MA: MIT Press.

Winkler, S. 2005. Ellipsis and Focus in Generative Grammar. Berlin: Mouton de Gruyter.

Winkler, S. 2016. Ellipsis and information Structure. In C. Féry and S. Ishihara (eds.), The Oxford Handbook of Information Structure, 359-382. Oxford: Oxford University Press.

Tancredi, C. 1992. Deletion, Deaccenting and Presupposition. PhD dissertation, MIT.

Umbach, C. 2005 . Contrast and information structure: A focus-based analysis of but. Linguistics 43 (1): 207-232.

Vallduví, E. and Vilkuna, M. 1998. On rheme and kontrast. In P. Culicover and L. McNally (eds.), The Limits of Syntax, 79-108. New York: Academic Press.

Van Valin, R. and LaPolla, R. 1997. Syntax: Structure, Meaning, and Function. Cambridge: Cambridge University Press.

Velleman, L. and Beaver, D. 2016. Question-based models of information structure. In C. Féry and S. Ishihara (eds.), The Oxford Handbook of Information Structure, 86-107. Oxford University Press.

Zeevat, H. 2004. Contrastors. Journal of Semantics 21: 95-112. 